The Research Journal of the Costume Culture

[Original Article]

Received June 30, 2017

Revised August 17, 2017

Accepted August 28, 2017

${ }^{\dagger}$ Corresponding author

(ziniko@konkuk.ac.kr)

ORCID

Hyobin Im

http://orcid.org/0000-0002-3734-8612

Hyunzin Ko

http://orcid.org/0000-0001-8763-3422

\section{The analysis of the characteristic types of motion recognition smart clothing products}

\author{
Hyobin Im and Hyun Zin $\mathrm{Ko}^{\dagger}$ \\ Dept. of Apparel Design, Konkuk University, Korea \\ 동작인식 스마트 의류제품의 특징적 유형 분석 \\ 임 효 빈·고 현 진 ${ }^{\dagger}$ \\ 건국대학교 의상디자인과
}

\begin{abstract}
The purpose of this study is to utilize technology as basic data for smart clothing product research and development. This technology can recognize user's motion according to characteristics types and functions of wearable smart clothing products. In order to analyze the case of motion recognition products, we searched for previous research data and cases referred to as major keywords in leading search engines, Google and Naver. Among the searched cases, information on the characteristics and major functions of the 42 final products selected on the market are examined in detail. Motion recognition for smart clothing products is classified into four body types: head \& face, body, arms \& hands, and legs \& feet. Smart clothing products was developed with various items, such as hats, glasses, bras, shirts, pants, bracelets, rings, socks, shoes, etc., It was divided into four functions health care type for prevention of injuries, health monitor, posture correction, sports type for heartbeat and exercise monitor, exercise coaching, posture correction, convenience for smart controller and security and entertainment type for pleasure. The function of the motion recognition smart clothing product discussed in this study will be a useful reference when designing a motion recognition smart clothing product that is blended with IT technology.
\end{abstract}

Keywords: motion sensing(동작인식), contact-based motion recognition(접촉식 동작 인식), non contact-based motion recognition(비접촉식 동작인식), motion sensor(모션센서), wearable smart clothing product(웨어러블 스마트 의류 제품)

\section{Introduction}

최근 IT 기술의 발달로 다양한 기능을 수행하는 스마트 기기의 개발이 증가하면 서 몸에 착용하여 컴퓨팅할 수 있는 웨어러블 디바이스의 보급률이 높아지고 있다. 착용 가능한 웨어러블 디바이스는 소형화되어 있어 이제 사용자와 한 몸처럼 움직 일 수 있는 편리함을 추구하며, 사용자 중심의 인터페이스로 변화되고 있다. 사용 
자 중심의 인터페이스는 인식 대상에 따라 음성인식, 동작인식, 뇌파인식 등으로 나누어지며, 이 중 동작인 식기술은 사용자의 직관적이고 일상적인 동작을 자 연스럽게 파악하여 기존의 입력방식에 대한 대안으 로 시장의 주목을 받고 있다.

동작인식은 가상/증강 현실을 위한 인터페이스로 의 사용이나 컴퓨터 게임, 애니메이션, 영화 등에서 캐릭터들의 사실적인 생동감 표현과 개인의 건강상 태를 관리하기 위한 건강정보 모니터링, 좀 더 효율 적인 스포츠 활동을 위한 스포츠 동작교육, 재활치료, 자세교정 등 특정 목적 달성을 위해 연구되어지고 있 으며, 그 활용 분야도 점점 확대되고 있는 추세이다. 이처럼 동작인식 기술은 영화, 게임, 스포츠, 헬스케 어, 교육, 재활치료 분야 등을 중심으로 사용자의 동 작을 분석하여 사용자의 편의 및 삶의 질 향상에 기 여하고자 연구되어져 왔으며, 의류분야에서도 IT 기 술과 섬유산업이 결합된 기술들이 융·복합되어 착용 자의 동작을 인식할 수 있는 제품이 개발되어 등장하 고 있다.

지금까지 동작인식에 관련한 선행연구는 동작인식 을 위한 시스템 개발에 관한 연구(Jung, Park, \& Choi, 2009; Lee, 2016; Son, 2006), 동작인식을 이용한 모 션분석에 관련된 연구(Heo \& Ha, 2015; Lee \& Kwon, 2016), 동작인식 기술을 적용한 게임개발 연구(Chae, 2014; Jang, 2012; Yoon \& Park, 2013), 동작인식 기 술 및 동향에 관한 연구(Cha, Ha, Lee, \& Kim, 2015; Chang, Ryu, \& Park, 2014; Ryu, 2015), 동작인식 방 법을 제안한 연구(Kim et al., 2009; Lee, Kim, \& Kim, 2010) 등 동작인식 기술에 대한 연구는 꾸준히 발표 되고 있지만, 효율적인 동작인식의 방법을 위한 시스 템 개발 및 동작인식에 관한 기술적인 측면만을 나열 한 것으로써 동작인식 의류제품과 관련된 연구는 부 족한 실정이다.

이에 본 연구는 최근 동작 인식에 관한 기술 개발 이 활발히 이루어지고 있는 웨어러블 디바이스 기반 동작인식 스마트 의류제품의 특징적 유형 및 기능에 따른 기술 및 동향을 조사, 분석하여 계속적으로 개 발이 진행되고 있는 사용자 동작인식을 위한 스마트 의류제품의 연구 및 개발을 위한 방향설정에 기초자 료로 활용하고자 한다. 본 연구에 있어 동작인식 스 마트 의류제품의 특징적 유형 및 기술을 분석하기 위
하여 문헌연구와 사례연구를 병행하였다. 먼저 관련 선행연구와 관련기사, 기술서, 보고서 등 다양한 문헌 자료에 관한 리서치를 바탕으로 동작인식에 대한 의미 및 기술의 개념을 살펴보았고, 인식방법에 따라 접촉 식과 비접촉식으로 구분하여 동작인식 기술을 고찰 하였다. 사례분석을 위한 제품 관련 자료 수집 방법은 대표적 검색엔진인 네이버(www.naver.com)와 구글 (www.google.com)에서 스마트 웨어, 스마트 의류, 웨 어러블 디바이스, 웨어러블 테크놀로지, 모니터링 스 마트 제품, 액티비티 트래커 등 6개의 한영 키워드로 1 차 검색을 실시한 후 도출된 제품들 중 2차 핵심 키 워드인 동작인식, 모션인식, 모션센싱, 움직임 인식 등 으로 검색되고 있는 사례와 선행연구 자료에서 2차 핵 심 키워드가 언급된 사례들 중 유사 제품들을 정리하 고, 2010년 이후부터 현재까지 출시되어 시판되고 있 는 최신 버전의 제품들로 최종 42 개의 제품들을 선정 하였다. 선정된 모션인식 스마트 의류제품들은 모자, 안경, 셔츠, 밴드, 반지, 양말, 깔창, 신발 등 다양한 웨 어러블 아이템으로 나타났다. 신체영역별 움직임 동작 이 다르므로 모션인식 스마트 의류제품을 착용하는 신체 영역별 유형으로 분류하였고, 해당 브랜드 홈페 이지와 관련 기사 등을 통해 수집한 자료들을 바탕으 로 특성 및 주요 기능들에 대한 정보를 구체적으로 탐색하였다. 또한 신체영역별 동작인식 스마트 의류 제품들의 특징적 유형 및 기능을 동작인식에 대한 기 술적 측면에서 분석하였다.

\section{Definition and Type of Motion Recognition Technology}

\section{Motion recognition technology}

동작인식(motion recognition)은 동작(motion)과 인 식(recognition)이 결합된 말로 사람의 신체 부위인 몸 통 - 손 - 발 등의 움직임을 감지하여, 어떠한 자세를 취했는지, 어떠한 행동을 행하고 있는지를 파악하고 분석하는 것으로 단순한 움직임에서부터 연속적인 움직임을 모두 포함한다. 동작인식 기술이란 카메라 나 동작인식센서 및 장치를 통하여 사용자의 신체 움 직임 정보를 획득하고, 획득한 데이터를 디지털신호 로 바꾸어 컴퓨터가 인식하는 기술을 말한다.

동작 인식을 위해 주로 사용되는 센서는 관성측정 
장치(Inertial Measurement Unit: IMU)로서, 하나의 IMU 센서에는 물체의 회전을 감지하는 자이로 센서, 속도 의 변화를 감지하는 가속도 센서, 지구 자기장에 대한 센서의 방향을 감지하는 지자기 센서가 통합되어(Cha et al., 2015) 3차원 공간에서 자유로운 움직임을 인지 하고, 이동 패턴을 산출한다. 자이로, 가속도, 지자기 센서들은 이동 또는 회전하면서 발생하는 데이터가 변화량만큼의 수치화 형태로 나타나기 때문에 모션 인식 활용에 적합하다(Kwon, Choi, Lim, \& Joung, 2016). 미세전자기계시스템(Micro Electro Mechanical System: MEMS)을 활용한 센서 제작기술의 발달은 소형화, 저전력화 등을 구현하여 사용자의 모션 및 이동정보를 추적하는 착용 가능한 의류제품으로까지 확대되어져 동작인식 기술이 가속화되고 있다.

\section{Type of motion recognition technology}

동작인식은 신체의 접촉 여부에 따라 접촉식 방식 과 비접촉식 방식으로 구분된다. 접촉식 동작인식기 술은 센서나 장치를 사용자 신체에 접촉하여 획득한 데이터를 동작인식에 이용하는 방식으로 이는 센서 및 장치가 신체에 직접 접촉되기 때문에 사용자의 정확 한 동작데이터 취득이 가능하나, 장비를 착용해야 하 는 불편함으로 사용자의 움직임이 부자연스러울 수 있다(Lim, Kim, \& Kim, 2012).

접촉식 동작인식 방식은 센서 및 장치를 포함한 컨 트롤 디바이스의 부착위치 및 사용형태에 따라 hand holder형, wearable형, 체중계 형으로 구분할 수 있다 (Yoon, 2014). Hand holder형은 손에 들고 있는 컨트 롤러를 통하여 사용자의 움직임을 인식하고, 게임 및 화면을 제어하는 것으로 스마트폰, 게임기, 스마트 $\mathrm{TV}$ 리모컨 등이 있다. Wearable형은 사용자의 신체 에 착용하여 움직임을 인식하는 것으로 디바이스의 신체 부착위치에 따라 머리, 몸통, 팔과 손, 다리와 발 4부위로 나누어지며, 제품으로는 모자, 안경, 귀걸이, 슈트, 시계, 밴드, 반지, 신발, 깔창, 발찌, 양말 등이 있다. 체중계형 동작인식은 디바이스 위에서의 움직 임을 압력센서를 통하여 인식하는 것으로 댄스게임 기, 닌텐도, Wii Fit 등이 있다. 이러한 접촉식 동작 인식기술 중 사용자의 신체에 부착하여 획득한 데이 터를 이용하는 웨어러블 형태가 최근 주목을 받고 있 으며(Ryu, 2015), 이는 초고속 네트워크와 근거리 무
선 통신기술, 초소형 센서기술, 저전력기술 등으로 웨 어러블 형태의 디바이스가 소형화, 저전력화, 경량화 되어 가능하게 되었다.

비접촉식 동작인식기술은 주로 카메라를 이용해 사용자의 움직임 정보를 추적하고 인식하는 시각기 술을 기반으로 하는 방식으로 사용자의 움직임은 자 연스럽지만 카메라나 센서의 범위를 벗어날 수 없는 단점과 함께 사용자 움직임에 대한 특징점을 찾고, 이를 추적하는데 기술적인 어려움이 있어(Lee, 2013) 정확한 데이터 획득이 어렵고, 정교한 움직임의 인식 에 한계가 있다(Yoo, 2016). 또한, 사용자 움직임을 실시간으로 빠르게 추적할 수 있으나, 카메라의 위치, 광원의 간섭, 그림자 등과 같은 외부 요인에 취약한 단점이 있어(Choi, 2014) 적외선인 깊이(depth)값을 이 용한 인식방법을 사용한다. 깊이 정보를 이용한 동작 인식 기술의 대표적인 사례로는 마이크로소프트의 동작인식 컨트롤러인 키넥트(Kinect)와 립모션(Leap Motion)이 있다(Kim \& Sung, 2014).

키넥트는 적외선 프로젝터와 RGB를 인식하는 일 반 카메라 모듈, 적외선을 인식하는 적외선 카메라와 같이 3 개의 렌즈로 구성되어 있다. 적외선 프로젝터가 픽셀 단위로 투사하고, 적외선 카메라가 이 픽셀들을 수 신한 뒤 픽셀간 거리 등으로 이미지의 3차원 좌표를 만들어 인식하게 된다(Korean Patent No. 10-1613431, 2016). Leap Motion은 저렴한 가격으로도 초고정밀 해상력과 빠른 인식 성능을 제공하며, 데스크톱과 같 은 근거리 환경에서 마우스를 대체하거나 문자 입력 을 지원하여 기존의 데스크탑 인터페이스를 어느 정 도 대체하고 있다(Seo, 2013). 립모션의 작동원리도 키넥트와 비슷하다. 적외선을 이용해 동작을 인식하 며, 키넥트보다 200 배 높은 감도를 가지며, $1 / 100 \mathrm{~mm}$ 의 움직임까지 감지한다(Kim \& Sung, 2014). 키넥트 가 모니터의 정면에 위치하여 동작을 인식한다면 립 모션은 화면 아래에 위치하여 손동작을 인식하며 컴 퓨터에 마우스와 키보드의 기능을 대신하여 입력 장 치로 사용되고 있다.

본 연구에서는 최근 주목받고 있는 웨어러블 형태 의 접촉식 동작인식 의류제품을 중심으로 센서 및 장 치를 포함한 디바이스의 신체 부착위치 및 접촉방식 에 따른 특성과 기능을 살펴보고, 사용목적에 따라 유형을 분류하여 살펴보고자 한다. 


\section{Type of Motion Recognition Smart Clothing Products by Body Area}

동작인식 스마트 의류제품을 착용하는 신체위치에 따라 머리와 얼굴, 몸통, 팔과 손, 다리와 발 4 부위로 나누어(Suh \& Roh, 2015) 제품 유형과 기능 및 주요 특성을 살펴보았다.

\section{Head and face}

머리와 얼굴에서 보여지는 동작인식 스마트 제품 은 모자와 안경, 이어링 등 액세서리 형태의 제품으 로 개발되고 있다. 생체 데이터 및 움직임 정보를 통 해 신체 보호 및 부상 방지를 위한 건강상태를 모니 터링하는 기능을 가지고 있다.

운동 중 머리의 충격을 LED 불빛으로 알려주어 부상방지에 도움을 주는 $\mathrm{MC10}$ 업체와 리복이 공동 으로 개발 한 체크라이트(Checklight)모자, 비정상적 인 움직임을 감지하여 사고 발생 시 머리와 목을 보 호하는 회브딩(HÖVDING)사의 자전거 전용 헬멧(Fig. $1)$, 칼로리 소모와 심박수를 체크해 활동 추적 및 건 강 상태를 모니터링 할 수 있는 라이프 빔 모자(Life BEAM hat)와 주울 귀걸이(Joule Earing)(Fig. 2), 눈 동자의 움직임 및 눈의 깜박임을 감지해 건강신호를 알려주는 진스 밈(JINS MEME) 안경(Fig. 3) 등이 대 표적 아이템이다. 이 중 진스 밈 안경은 사용하는 앱 에 따라 안구활동을 통해 졸음운전을 방지할 수 있도 록 졸음 정도를 알리고, 경고하거나 뛰는 자세를 통 해 운동 내용 기록과 자세를 바로 잡을 수 있도록 운 동 모니터링 기능도 가능한 제품이다(Reinia, 2015).

\section{Torso}

몸통에서 보여지는 동작인식 스마트 제품은 브라, 셔츠, 팬츠, 풀 바디슈트와 같은 의복형태가 주를 이 루고 있다. 심장박동과 호흡 같은 생체 데이터 모니 터링을 통한 건강상태와 운동량 분석 기능이 주를 이 루고 있다.

캐나다 옴시그널(Omsignal)의 옴브라(OMbra)(Fig. 4), 미국 빅토리아 시크릿(Victoria secret)의 스마트 스 포츠 브라(Smart sports Bra)와 미국 랄프로렌(Ralph Lauren)과 캐나다 옴시그널(Omsignal)이 함께 손잡고 제작한 폴로 테크(Polo tech)(Fig. 5), 블랙야크(BLACK
YAK)의 야크 온 P(Yak ON P), 미국 센소리아(Sensoria)의 스마트 티셔츠(Smart T- Shirt), 캐나다 헥소스 킨(Hexoskin)(Fig. 6), 프랑스 시티즌 사이언스(Cityzen Science)의 D-shirts 등은 상의 제품으로 운동 시 착용 자의 생체신호를 실시간으로 측정하여 이동한 거리, 심장박동, 소모된 칼로리, 운동 레벨 정도 등 운동 상 태와 성과를 사용자에게 알려준다. 상의와 하의 세트 로 구성된 미국 MAD Apparel사의 아토스(Athos)(Fig. 7), 미국의 엔플럭스(Enflux)(Fig. 8), 캐나다의 헤도코 (Heddoko)는 운동 시 실시간으로 자신의 운동모습을 $3 \mathrm{D}$ 아바타를 통해 나의 운동 자세와 표준자세를 함 께 보여주어 트레이너와 학습하는 것과 같은 기능을 제공하여 혼자서도 자세교정이 가능한 제품이다. 필란 드 마이온텍(Myontec)의 엠바디(Mbody)는 반바지 형 태의 의복으로 근육의 움직임 및 근육의 좌우/앞뒤 발란스 등을 휴대폰을 통해 실시간으로 볼 수 있고, $\mathrm{PC}$ 에서 움직임의 상태 분석도 가능하다. 미국 레스트 디바이스(Rest Devices)사의 풀 바디 슈트인 미모(Mimo) 는 아기의 호흡, 자세, 활동 상태 등을 감지하고 모니 터링하여 이상이 발생하면 경보음이 울린다. 미국의 루모 바디 텍(Lumo Body Tech)사의 루모백(Lumoback) (Fig. 9)은 사용자의 자세가 바르지 않으면 진동이 울 려 바른 자세를 유지할 수 있도록 도움을 주는 허리 벨트로 데이터를 누적해 시간대별로 구분해서 확인 가능한 제품이다(Kim, 2013).

\section{Arm and hand}

팔과 손 부위의 제품은 밴드, 반지 등과 같은 액세 서리 형태의 제품 등으로 개발되고 있으며, 손과 팔 의 움직임을 통해 스마트 기기를 컨트롤하거나 신체 바이오리듬으로 건강정보 제공 및 운동량 측정과 보안 인증, 운동 코칭 등의 기능적인 요소뿐만 아니라, 다 양한 색상으로 패션 액세서리의 장식적인 요소도 함 께 가지고 있다.

미국 RHL비전테크놀로지(RHL vision technology) 사의 핀(Fin)링(Fig. 10), 일본 로그바(Logbar)사의 링 (Ring)(Fig. 11), 한국 유즈브레인넷(UZbrainnet)사의 모션 링(Motion ring) 등은 반지 형태의 제품으로 손 가락의 움직임을 통하여 컴퓨터나 주변의 스마트 기 기의 입력, 작동, 제어가 가능한 컨트롤러 기능을 가 지고 있다. 밴드 제품으로는 사용자의 심박수 및 움 
직임을 통하여 칼로리 소모량, 하루 활동량, 운동시간 등 운동량을 모니터링하고, 사용자가 목표를 달성할 수 있도록 정보를 제공하는 미국 핏빗(Fitbit)사의 핏 빗 차지 HR(fitbit charge HR)밴드, 중국 샤오미(Xiao$\mathrm{mi}$ )사의 미 밴드(Mi band), 미국 조본(Jawbone)의 조 본 업(Jawbone Up)밴드, 미국 나이키와 애플(Nike \& Apple)사의 퓨얼밴드(Fuel band)(Fig. 13), 한국 인바 디(Inbody)사의 인바디 밴드(Inbody band)와 사용자 고유의 심장박동이나 특정한 동작으로 잠금이 해제되 는 보안 인증 기능을 가진 캐나다 바이오님(Bionym) 사의 나이미(Nymi)밴드, 상황에 맞는 효과음을 구현 해주는 스마트 장난감인 일본 모프(Moff)사의 모프 (Moff)밴드, 착용자의 테니스 운동경기를 분석해서 운동이 끝난 후에 효과적인 경기운영을 할 수 있도록 정보를 제공하는 오스트레일리아 벤처기업(Venture Company)의 스매쉬(Smash)밴드, 동작인식 기반의 근 육감지 입력장치 기능을 가진 미국 탈믹랩(Thalmic $\mathrm{Lab}$ )의 마이요(Myo) 암밴드(armband)(Fig. 12) 등이 있다.

\section{Legs and feet}

다리와 발에 착용하는 동작인식 스마트 제품은 발 찌, 양말, 깔창, 신발 등으로 개발되고 있다. 양말, 깔 창, 신발은 발바닥에 가해지는 압력분포를 통해 신체 하중의 균형감 및 걸음걸이 등의 건강상태를 체크하 고, 운동량 및 운동 자세를 측정하는 기능을 가지고 있다.

발찌제품으로는 다리의 움직임을 통하여 속도, 거 리, 시간, 활동량 등의 정보를 알려주는 미국 플라이 피트(Flyfit) 피트니스 밴드(Fitness band)(Fig. 14)와 아기의 심박수를 측정하여 정상적이지 않은 상태를 감지하면 부모의 스마트폰으로 알려주는 미국 스프 라우틀링(Sproutling)사의 베이비 모니터(Baby Monitor)(Fig. 15)가 있다. 양말은 발바닥의 압력센서를 통 하여 사용자의 걸음걸이를 측정하는 미국 센서리아 (Sensoria)사의 스마트 양말(Smart socks)(Fig. 16)과 심장박동, 산소포화도 등과 같은 호흡을 모니터링하 는 미국 아웃렛(Owlet)의 베이비 모니터 스마트 양말 (Baby monitor's smart socks)이 있다. 깔창은 걸음걸 이나 달리기 자세의 흐트러짐을 감지하는 당뇨병 환 자를 위해 고안된 프랑스 신생기업 핏미(FeetMe)사의
스마트 깔창 핏미(FeetMe)(Fig. 17), 활동량과 신체의 균형 및 건강을 체크할 수 있는 한국 비엠시스(BMsys) 사의 핏 가이더(Feet Guider), 자세교정 및 건강정보 를 제공하는 한국 쓰리엘 랩스(3L Labs)의 풋 로거 (Foot Logger), 달리기 자세를 실시간으로 분석하여 자신의 달리기 양식을 개선하고, 운동장애 방지와 무 릎부상 예방을 위한 영국 ReTiSense사의 Stridalyzer (Fig. 18) 등이 있다. 신발은 발 움직임을 감지하여 착 용자의 모든 운동 활동을 관리해주는 스마트한 제품 으로 운동량 및 이동정보를 추적하는 미국 나이키 (Nike)사의 나이키 플러스(NIKE + )와 바른 자세와 적 절한 스피드로 조깅 같은 운동을 할 수 있도록 도와 주는 미국 알트라러닝(Altrarunning)사의 알트라 헤일 로 테크 슈(Altra Halo Tech Shoe)(Fig. 19), 골프 스 윙 시 양 발의 밸런스, 무게중심 이동, 지지력 등 자 신의 자세뿐만 아니라, 다른 플레이어의 스윙과 비교 해 피드백을 제공하는 한국 솔티드 벤처(SALTED VENTURE)사의 아이오핏(Iofit)(Fig. 20) 골프화 등이 있다.

지금까지 살펴 본 동작인식 스마트 의류제품의 신체 부위별 유형 및 제품의 주요 특성을 정리해 보면 〈Table 1〉과 같다.

\section{The Analysis of the Type of Motion Recognition Smart Clothing Products}

신체부위별 동작인식 스마트 의류제품의 특성과 기 능을 고찰한 결과, 사용목적에 따라 4 가지 유형인 헬스 케어(healthcare)형, 스포츠(sports)형, 생활편의형(convenience), 엔터테인먼트(entertainment)형으로 분류하 고, 기능별 세부기술을 분석하였다.

\section{Healthcare type}

헬스케어형(healthcare type)은 동작인식 스마트 의류 제품을 통해 사용자의 생체 신호 및 움직임이 측정, 분석되어 사용자나 보호자에게 건강상태가 전달됨으 로써 신체보호 및 건강 유지 관리와 질병 예방을 위 한 즉각적인 행동이 가능할 수 있도록 하는 기능을 가 진 제품을 의미한다. 개발된 헬스케어형 제품은 신체 보호를 위한 부상방지용, 생체신호 및 활동상태 감지 를 통한 건강모니터링용, 잘못된 자세로 인해 건강에 

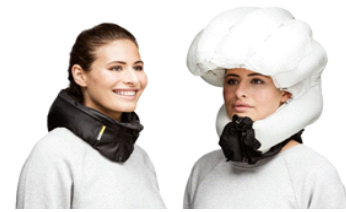

<Fig. 1> Hövdings 2.0 airbag Helmet: Hövding. From. Hövding. (n.d.). https://shop.hovding.com

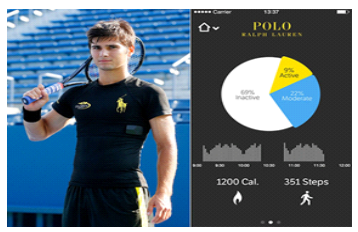

<Fig. 5> PoloTech ${ }^{\mathrm{TM}}$ : Ralph Lauren.

From. Jo. (2014). http://www.itnk.co.kr

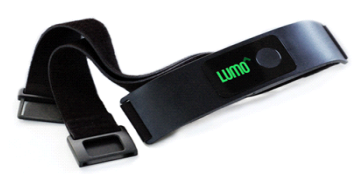

<Fig. 9> LUMOback: Lumo Bodytech.

From. Kim, B. J. (2013). https://www.appstory.co.kr
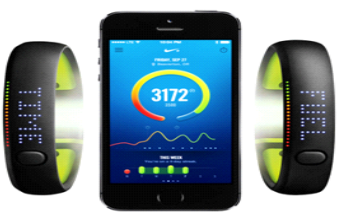

<Fig. 13> Fuel Band: NIKE \& Apple.

From. Kim, M. K. (2013). http://www.kinews.net
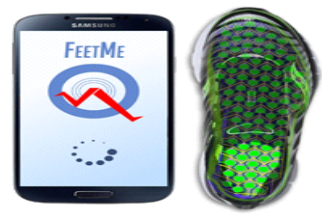

<Fig. 17> FeetMe: FeetMe.

From. Sin. (2015).

http://www.bizion.com
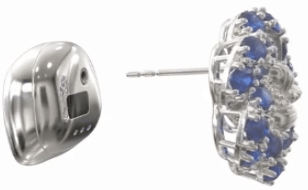

<Fig. 2> Joule Earing: BioSensive.

From. BioSensive

Technologies. (n.d.). http://shopjoule.com

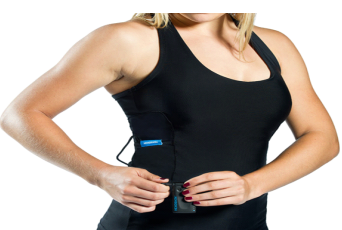

<Fig. 6> Hexoskin shirt: Hexoskin.

From. Hexoskin. (n.d.). https://www.hexoskin.com

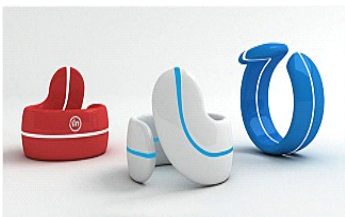

<Fig. 10> Fin ring: RHL vision.

From. Choi. (2015).

http://navercast.naver.com

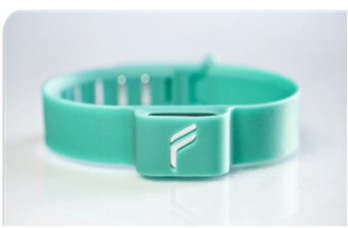

<Fig. 14> Fly Fit: Fly Fit.

From. Lee. (2014). http://techholic.co.kr

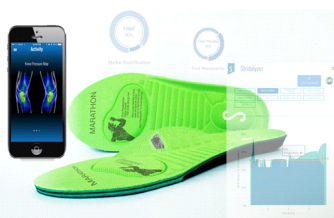

<Fig. 18> Stridalyzer: ReTiSense.

From. ReTiSense. (2015). http://www.retisense.com
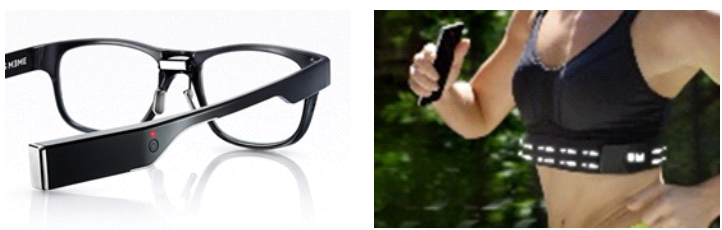

<Fig. 3> Jins MEME: Jins. <Fig. 4> OMbra: Omsignal. From. Jins EMEM. (n.d.). From. Omsignal. (n.d.). https://jins-meme.com https://www.omsignal.com

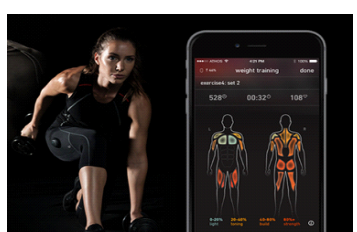

<Fig. 7> Athos: Athos.

From. Athos. (n.d.).

https://www.liveathos.com

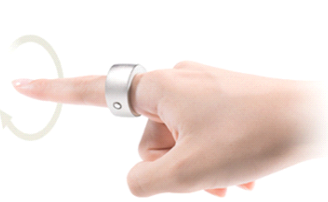

<Fig. 11> Logbar ring: Logbar.

From. Jeon. (2015a). http://biz.newdaily.co.kr

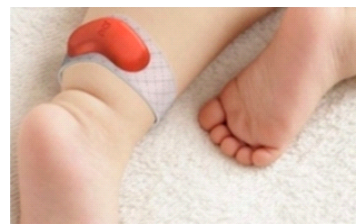

<Fig. 15> Baby monitor: Sproutling.

From. sproutling. (2015). https://sproutling.com

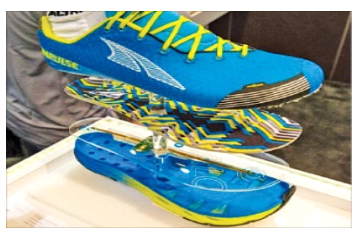

<Fig. 19> Altra Halo Tech Shoe: Altrarunning.

From. Jeon. (2015b). http://biz.newdaily.co.kr

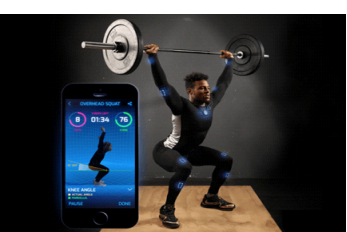

<Fig. 8> Enflux Smart Clothing: Enflux.

From. Chang. (2016). https://www.digitaltrends.com

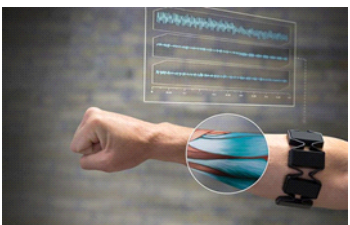

<Fig. 12> Myo:

Thalmic Labs.

From. Thalmic Labs. (n.d.). https://www.myo.com
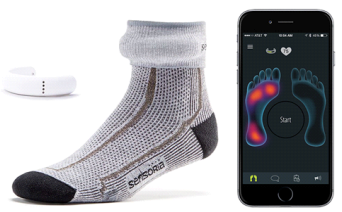

<Fig. 16> Sensoria socks: Sensoria.

From. Sensoria. (n.d.). http://www.sensoriafitness.com

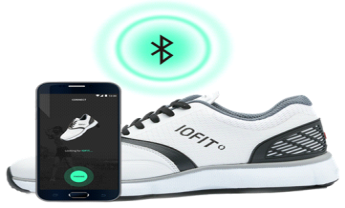

<Fig. 20> Iofit shoes: Salted Venture.

From. Salted Venture. (2017). http://iofitshoes.com 
<Table 1> Motion recognition smart clothing products by body area

\begin{tabular}{|c|c|c|c|c|c|}
\hline & Item & Brand & Product & Country(Year) & Character \\
\hline \multirow{5}{*}{$\begin{array}{l}\text { Head } \\
\& \\
\text { face }\end{array}$} & \multirow{3}{*}{ Hat } & Reebok \& MC10 & Checklight & USA(2013) & Head impact detection and injury prevention \\
\hline & & Hövding & $\begin{array}{l}\text { Hövdings } 2.0 \\
\text { airbag }\end{array}$ & Sweden(2013) & $\begin{array}{l}\text { Abnormal motion detection } \\
\text { Head and neck protection }\end{array}$ \\
\hline & & Life Beam & Smart Hat & Israel(2014) & $\begin{array}{l}\text { Bio-signal in real time measurement } \\
\text { Calorie, heart rate check, activity tracking }\end{array}$ \\
\hline & Earing & $\begin{array}{l}\text { BioSensive } \\
\text { Technologies }\end{array}$ & Joule & Canada(2017) & $\begin{array}{l}\text { Calorie, heart rate check, activity tracking } \\
\text { Health status monitoring }\end{array}$ \\
\hline & Glass & Jins & JINS MEME & $\operatorname{Japan}(2015)$ & $\begin{array}{l}\text { Eye movement, blink detection } \\
\text { Health, drowsiness and fatigue monitoring }\end{array}$ \\
\hline \multirow{13}{*}{ Torso } & \multirow{2}{*}{ Bra } & Omsignal & OMbra & Canada(2014) & \multirow{7}{*}{$\begin{array}{l}\text { Bio-signal in real time measurement } \\
\text { Calorie, heart rate check, activity tracking } \\
\text { Exercise level, status, performance }\end{array}$} \\
\hline & & Victoria'secret & Smart Sports Bra & USA(2014) & \\
\hline & \multirow{5}{*}{ Shirt } & Ralph Lauren & PoloTech $^{\mathrm{TM}}$ & USA(2014) & \\
\hline & & Omsignal & Smart Shirts & Canada(2014) & \\
\hline & & BLACK YAK & YAK ON P & Korea(2015) & \\
\hline & & Hexoskin & Hexoskin & Canada(2014) & \\
\hline & & Cityzen Sciences & D-Shirts & France(2014) & \\
\hline & & MAD apparel & Athos & USA(2014) & Bio-signal in real time measurement \\
\hline & $\begin{array}{l}\text { Shirt }+ \\
\text { pants }\end{array}$ & Enflux & Enflux & USA(2016) & $\begin{array}{l}\text { Measuring muscle movement } \\
\text { Exercise posture displayed as 3D avatar }\end{array}$ \\
\hline & & Heddoko & Heddoko & Canada(2015) & $\begin{array}{l}\text { Joint motion measurement } \\
\text { Exercise posture displayed as } 3 \mathrm{D} \text { avatar }\end{array}$ \\
\hline & Pants & Myontec & Mbody & Finland(2014) & $\begin{array}{l}\text { Measuring biometric. } \\
\text { Measure muscle movement. }\end{array}$ \\
\hline & $\begin{array}{l}\text { Body } \\
\text { suit }\end{array}$ & Rest Device & MIMO & USA(2014) & $\begin{array}{l}\text { Bio-signal in real time measurement } \\
\text { Health status monitoring }\end{array}$ \\
\hline & Belt & Lumo Bodytech & Lumoback & USA(2012) & $\begin{array}{l}\text { Waist posture displayed as an avatar. } \\
\text { Posture correction. }\end{array}$ \\
\hline \multirow{7}{*}{$\begin{array}{l}\text { Arm } \\
\& \\
\text { hand }\end{array}$} & \multirow{7}{*}{ Band } & Venture company & Smash & Australia(2015) & $\begin{array}{l}\text { Analysis of tennis game. } \\
\text { Coaching according to your abilities. }\end{array}$ \\
\hline & & Bionym & Nymi & Canada(2014) & $\begin{array}{l}\text { Heart rhythm pattern and motion recognition } \\
\text { Security certification }\end{array}$ \\
\hline & & Fitbit & Fitbit charge HR & USA(2015) & \multirow{5}{*}{$\begin{array}{l}\text { Exercise and physical activity measurement } \\
\text { (Calorie consumption, exercise time, } \\
\text { distance, number of steps) }\end{array}$} \\
\hline & & Xiaomi & Mi band & China(2014) & \\
\hline & & Jawbone & Jawbone up & USA(2013) & \\
\hline & & NIKE \& Apple & Fuel band & USA(2013) & \\
\hline & & Inbody & Inbody band & Korea(2016) & \\
\hline
\end{tabular}


$<$ Table 1> Continued

\begin{tabular}{|c|c|c|c|c|c|}
\hline & Item & Brand & Product & Country(Year) & Character \\
\hline \multirow{5}{*}{$\begin{array}{l}\text { Arm } \\
\& \\
\text { hand }\end{array}$} & \multirow{2}{*}{ Band } & Moff & Moff band & $\operatorname{Japan}(2016)$ & Provides sound effects after detecting motion. \\
\hline & & Thalmic Labs & Myo & USA(2013) & Muscle detection Smart Device Control \\
\hline & \multirow{3}{*}{ Ring } & $\begin{array}{l}\text { RHL vision } \\
\text { technology }\end{array}$ & Fin & USA(2015) & \multirow{3}{*}{ Motion detection Smart device control. } \\
\hline & & Logbar & Logbar ring & $\operatorname{Japan}(2014)$ & \\
\hline & & Uzbrainnet & Motion ring & Korea(2014) & \\
\hline \multirow{11}{*}{$\begin{array}{l}\text { Legs } \\
\& \\
\text { feet }\end{array}$} & \multirow[t]{2}{*}{ Anklet } & Flyfit & Flyfit & USA(2014) & $\begin{array}{l}\text { Exercise and physical activity measurement } \\
\text { (Speed, distance, time, calorie consumption) }\end{array}$ \\
\hline & & Sproutling & Baby monitor & USA(2014) & Measurement of vital signs, sleep patterns. \\
\hline & \multirow[t]{2}{*}{ Socks } & Sensoria & Smart socks & USA(2013) & $\begin{array}{l}\text { Exercise and physical activity measurement } \\
\text { (Speed, distance, time, heart rate) } \\
\text { Gait measurement, posture correction }\end{array}$ \\
\hline & & Owlet & Smart socks & USA(2014) & $\begin{array}{l}\text { Measurement of vital signs, breathing } \\
\text { (Heart rate, oxygen saturation, body temperature) }\end{array}$ \\
\hline & \multirow{4}{*}{ Insole } & ReTiSense & Stridalyzer & England(2015) & $\begin{array}{l}\text { Analysis of walking, running posture. } \\
\text { Injury prevention. }\end{array}$ \\
\hline & & BMSYS & Feet guider & Korea(2015) & $\begin{array}{l}\text { Body balance and health check, } \\
\text { Provides customized exercise methods. }\end{array}$ \\
\hline & & Feetme & Feetme & France(2015) & $\begin{array}{l}\text { Analysis of foot and running postures. } \\
\text { Providing health information } \\
\text { Designed for diabetic patients. }\end{array}$ \\
\hline & & 3L Labs & Foot Logger & Korea(2015) & $\begin{array}{l}\text { Body load balance detection. Step analysis. } \\
\text { Providing health information }\end{array}$ \\
\hline & \multirow{3}{*}{ Shoes } & Altrarunning & Altra Halo Tech & USA(2015) & $\begin{array}{l}\text { Correct posture, pressure distribution } \\
\text { measurement. Fatigue and injury prevention. }\end{array}$ \\
\hline & & NIKE & NIKE+ + & USA(2010) & $\begin{array}{l}\text { Measure distance, calories, time and } \\
\text { momentum during exercise. } \\
\text { Exercise capacity measurement. }\end{array}$ \\
\hline & & Salted Venture & Iofit golf & Korea(2017) & Golf pose analysis and comparison. \\
\hline
\end{tabular}

무리가 가지 않도록 체크해주는 자세교정용으로 분 류된다. 부상방지용은 비정상적인 움직임을 모션센서 가 감지하여 제품이 자동으로 부풀어 올라 착용자의 목과 머리를 보호하는 자전거 전용 헬멧과 운동 시 머리 충격 정도를 가속도 센서, 각속도 센서로 감지 하여 LED 불빛으로 코치나 보호자에게 알림을 주어 부상을 방지할 수 있도록 도움을 주는 Checklight 모 자가 있다. 부상방지용 제품들은 보호하고자 하는 신 체 위치에 센서가 부착되어 사용되고 있다.
건강모니터링 제품으로는 착용자의 호흡, 심박수, 체온, 자세 등 생체신호 및 활동상태를 감지하여 보 호자에게 알려주는 Mimo, Sproutling 발찌, Owlet Baby Monitor 양말 등과 같은 유아용 제품과 사용자 본인 에게 알림을 주어 스스로 건강상태를 확인할 수 있는 JINS MEME 안경과 Joule 귀걸이가 있다. 자세교정 용은 착용자의 움직임을 파악해 바른 자세를 유지할 수 있도록 정보를 제공하는 제품으로 가속도 센서를 이용하여 신체의 움직임을 파악하고, 사용자가 잘못 
된 자세를 취할 때 알림을 주는 Lumoback 허리벨트 와 발바닥의 압력센서에 가해지는 압력분포를 측정 하여 착용자의 신체의 균형 및 자세의 흐트러짐을 감 지하여 자세교정과 건강정보를 제공하는 FeetMe, FeetGuider, Foot Logger 등의 신발깔창이 있다.

헬스케어형은 모자, 안경, 벨트, 깔창 등 액세서리 형태 제품으로 주로 출시되어 개인의 질병 예방 및 건 강관리를 위해 사용자 또는 보호자에게 착용자의 건강 정보를 제공해주는 건강 모니터링용으로 활용되고 있다.

\section{Sports type}

스포츠형(sports type)은 특성화된 전문 스포츠 활 동 시 착용하는 제품으로 동작인식 스마트 의류제품 을 통해 착용자의 운동 시 수행되는 움직임 데이터를 수집 분석하여 보다 과학적인 피드백 제공 등 운동정 보 제공 기능을 주목적으로 하는 동작인식 스마트 의 류제품군이다. 개발된 스포츠형 제품으로는 경기력을 향상시키기 위해 운동량 및 운동 활동을 모니터링하 는 운동모니터링용 제품, 착용자의 행동 분석을 통해 운동정보를 제공하는 코칭용 제품, 올바른 자세정보 를 제공하는 자세교정용 제품으로 분류된다. 운동모 니터링용 제품은 상의에 착용하는 브라와 셔츠 형태 의 의복과 발목, 손목에 착용하는 밴드타입이 주를 이루고 있다. 심박센서와 가속도센서를 이용하여 심 박수 등 신체의 바이오리듬을 측정하거나, 칼로리 소 모량, 하루 활동량, 운동시간 등 사용자의 움직임 양 을 측정하여 정보를 제공하고, $\mathrm{EMG}$ 센서를 통하여 근육의 움직임까지 모니터링하여 모바일 앱으로 운 동성과에 대한 분석 표시도 가능한 기능을 가지고 있 다. 코칭용 제품으로는 Smash밴드와 Nike+ 등이 있 으며, 착용자의 행동 데이터를 분석하여 효과적인 경 기운영을 할 수 있도록 운동정보를 제공한다. 자세교 정용은 인체에 밀착된 의복 또는 텍스타일 기반으로 된 양말, 인솔, 신발 등과 같은 액세서리 제품으로 잘 못된 자세로 인한 피로감 및 부상의 위험을 예방하거 나, 운동능력 향상을 위한 기능을 제공한다. 상의와 하의로 구성된 Enflux와 Heddoko는 여러 개의 센서 가 내장되어 자신의 운동모습을 $3 \mathrm{D}$ 아바타를 통해 알려주어 트레이너와 학습하는 것과 같은 자세교정 효과를 볼 수 있다. 인솔 및 신발 제품으로는 Stridalyzer, Sensoria smart socks, Altra Halo Tech Shoe,
Iofit이 있으며, 이 제품들은 압력센서와 가속도 센서가 내장되어 양발의 지지력 및 압력분포, 움직임을 인식 하고, 바른 자세로 운동할 수 있도록 도움을 준다.

스포츠형은 브라, 셔츠, 바지, 밴드, 깔창, 신발 등 의류와 액세서리 형태 제품으로 개발되어 사용자에게 스마트폰 연동을 기반으로 운동레벨, 운동속도, 이동 거리, 운동성과, 운동자세 등 다양한 운동정보를 알려 줌으로써 사용자 스스로 자신의 운동정보를 모니터 링하고, 효율적인 스포츠 활동을 할 수 있도록 도와 주는 기능을 제공한다.

\section{Convenience type}

생활편의형(convenience type)은 일상생활에서 간단 한 동작으로 컨트롤러 기능을 대신하는 생활편의 스 마트 상품으로 생체신호 및 몸의 움직임을 측정하고 분석하여 스마트 정보기기를 제어하는 스마트 컨트 롤러 기능과 개인의 고유 생체 정보를 통한 보안 기 능을 가지고 있다. 스마트 컨트롤러 형은 주로 액세서 리 형태인 핀(Fin)링, 로그바(Logbar)링, 모션(Motion) 링과 같은 반지형태의 제품이 지닌 기능으로 반지를 착용한 손가락의 움직임을 모션센서가 인식하여 스 마트폰뿐만 아니라, 블루투스와 연동된 주변의 장치 에 데이터를 전달함으로써 컴퓨터나 주변의 스마트 기기의 입력, 작동, 제어가 가능하여 움직임이 불편한 장애인들에게 도움을 줄 수 있다. 사용자의 팔에 착 용하여 사용하는 암밴드 형태의 입력장치인 $\mathrm{Myo}$ 는 팔 근육을 움직일 때 나오는 전기신호를 인식하여 주 변의 기기를 제어한다. 보안 인증 기능을 가진 바이 오님(Bionym)의 나이미(Nymi)밴드는 손목과 Nymi의 윗부분에 두 개의 전극을 가지고 있으며, 사용자의 손 가락을 통한 전류의 흐름을 이용해 심장박동 패턴을 인식하여 잠금이 해제되는 제품(Son, 2014)으로 생활 의 편의를 제공한다.

\section{Entertainment type}

엔터테인먼트형(entertainment type)은 동작인식 스 마트 의류제품을 통해 사용자의 움직임을 측정 분석 하여 오락 및 게임 놀이인 가상공간에서 사실적인 생 동감을 주어 사용자에게 재미를 제공하는 것을 의미 한다. 대표적인 제품인 모프(Moff)밴드는 시계형 장 난감으로 손목에 장착해 여러 동작을 취하면 가속도 
센서, 자이로센서를 통해 사용자의 움직임을 분석하 고, 스마트폰과 블루투스로 연결하여 사용자의 모션 에 따라 상황에 맞는 효과음을 구현해주어 재미를 제
공한다.

동작인식 스마트 의류제품 기능별 인식 및 센서 기 술을 정리해 보면〈Table 2〉와 같다.

$<$ Table 2> Technology by type of motion recognition smart clothing products

\begin{tabular}{|c|c|c|c|c|c|c|}
\hline \multirow[b]{2}{*}{ Type } & \multirow[b]{2}{*}{ Function } & \multirow[b]{2}{*}{ Product } & \multicolumn{4}{|c|}{ Technology } \\
\hline & & & Recognition & Feedback & Sensor & $\begin{array}{c}\text { Sensor } \\
\text { Contact area }\end{array}$ \\
\hline \multirow{7}{*}{$\begin{array}{l}\text { Health- } \\
\text { care }\end{array}$} & \multirow{2}{*}{$\begin{array}{l}\text { Injury } \\
\text { prevention }\end{array}$} & $\begin{array}{l}\text { ·Hövdings } 2.0 \\
\text { airbag }\end{array}$ & -Abnormal motion & $\begin{array}{l}\text {-Automatic air bag } \\
\text { operation }\end{array}$ & -Motion & $\cdot$ Neck \\
\hline & & - Checklight & $\begin{array}{l}\text { - Motion detection } \\
\text { due to head impact }\end{array}$ & $\begin{array}{l}\text { Shows LED light } \\
\text { (Guardian) }\end{array}$ & $\begin{array}{l}\cdot \text { Accelerometer } \\
\cdot \text { Gyroscope }\end{array}$ & $\cdot$ Head \\
\hline & \multirow{3}{*}{$\begin{array}{l}\text { Health } \\
\text { monitoring }\end{array}$} & $\begin{array}{l}\cdot \text { Mimo } \\
\cdot \text { Owlet baby } \\
\text { socks } \\
\cdot \text { Sproutling } \\
\text { monitor }\end{array}$ & $\begin{array}{l}\cdot \text { Vital signs when } \\
\text { sleeping }\end{array}$ & $\begin{array}{l}\text {-Smart phone } \\
\text { display(Guardian) } \\
\cdot \text { Alarm }\end{array}$ & $\begin{array}{l}\cdot \text { Heart rate } \\
\cdot \text { Acceleration }\end{array}$ & $\begin{array}{l}\cdot \text { Body } \\
\cdot \text { foot }\end{array}$ \\
\hline & & -Joule Earing & $\begin{array}{l}\text {-Vital signs when } \\
\text { activity }\end{array}$ & \multirow{3}{*}{$\begin{array}{l}\text { Smart phone } \\
\text { display }\end{array}$} & $\begin{array}{l}\cdot \text { Heart rate } \\
\cdot \text { Acceleration }\end{array}$ & ·Ear \\
\hline & & Jins meme & $\begin{array}{l}\cdot \text { Eye movement } \\
\cdot \text { Blink detection }\end{array}$ & & $\begin{array}{l}\cdot \text { EOG } \\
\cdot \text { Acceleration }\end{array}$ & $\begin{array}{l}\cdot \text { Nose } \\
\cdot \text { Glasses leg }\end{array}$ \\
\hline & \multirow{2}{*}{$\begin{array}{l}\text { Posture } \\
\text { correction }\end{array}$} & $\begin{array}{l}\cdot \text { Feet Me } \\
\cdot \text { Feet Guider } \\
\cdot \text { Foot Logger }\end{array}$ & Foot pressure & & $\begin{array}{l}\cdot \text { Pressure } \\
\cdot \text { Acceleration }\end{array}$ & $\begin{array}{l}\text { Sole of the } \\
\text { foot }\end{array}$ \\
\hline & & -Lumoback & - Waist posture & $\begin{array}{l}\cdot \text { Smart phone } \\
\text { avatar display } \\
\cdot \text { Vibration }\end{array}$ & -Lumo lift & -Waist \\
\hline \multirow{8}{*}{ Sports } & \multirow{6}{*}{$\begin{array}{c}\text { Heart rate } \\
\& \\
\text { exercise } \\
\text { monitoring }\end{array}$} & - Life beam hat & -Biological signal & & $\begin{array}{l}\cdot \text { Heart rate } \\
\cdot \text { Acceleration }\end{array}$ & - Forehead \\
\hline & & $\begin{array}{l}\cdot \text { Ombra } \\
\cdot \text {-Sports Bra } \\
\cdot \text { PoloTech } \\
\cdot \text { Yark on-P } \\
\cdot \text { Hexoskin } \\
\cdot \text { D-shirt }\end{array}$ & -Biological signal & $\begin{array}{l}\text { Smart phone } \\
\text { display }\end{array}$ & $\begin{array}{l}\cdot \text { Heart rate } \\
\cdot \text { Acceleration } \\
\cdot \text { Gyroscope }\end{array}$ & - Chest \\
\hline & & $\begin{array}{l}\cdot \text { Fitbit band } \\
\cdot \text {-Mi band } \\
\cdot \text { Jawbone Up } \\
\cdot \text { Fuelband } \\
\cdot \text {-Inbody band }\end{array}$ & \multirow[t]{2}{*}{$\begin{array}{l}\text {-All movements of } \\
\text { daily life } \\
\cdot \text { Exercise movements } \\
\cdot \text { Biological signal }\end{array}$} & \multirow{4}{*}{$\begin{array}{l}\text { Smart phone } \\
\text { display } \\
\cdot \text { Voice }\end{array}$} & \multirow[t]{2}{*}{$\begin{array}{l}\cdot \text { Heart rate } \\
\cdot \text { Acceleration }\end{array}$} & $\cdot$ Wrist \\
\hline & & $\cdot$ Fly Fit & & & & -Ankle \\
\hline & & -Athos & $\begin{array}{l}\cdot \text { Biological signal } \\
\cdot \text { Muscle move }\end{array}$ & & $\begin{array}{l}\cdot \text { Heart rate } \\
\cdot \text { EMG }\end{array}$ & $\begin{array}{l}\cdot \text { Chest, wrist } \\
\cdot \text { Arm, torso } \\
\cdot \text { Calf, leg }\end{array}$ \\
\hline & & -Mbody & - Muscle move & & $\cdot$ EMG & - Calf \\
\hline & \multirow{2}{*}{$\begin{array}{l}\text { Exercise } \\
\text { coaching }\end{array}$} & -Smash & \multirow{2}{*}{-Exercise motion } & \multirow{2}{*}{$\begin{array}{l}\text { Smart phone } \\
\text { display }\end{array}$} & \multirow{2}{*}{-Acceleration } & $\cdot$ Wrist \\
\hline & & $\cdot$ Nike+ & & & & Sole \\
\hline
\end{tabular}


$<$ Table 2> Continued

\begin{tabular}{|c|c|c|c|c|c|c|}
\hline \multirow[b]{2}{*}{ Type } & \multirow[b]{2}{*}{ Function } & \multirow[b]{2}{*}{ Product } & \multicolumn{4}{|c|}{ Technology } \\
\hline & & & Recognition & Feedback & Sensor & $\begin{array}{c}\text { Sensor } \\
\text { Contact area }\end{array}$ \\
\hline \multirow[b]{2}{*}{ Sports } & \multirow[b]{2}{*}{$\begin{array}{l}\text { Exercise } \\
\text { posture } \\
\text { correction }\end{array}$} & $\begin{array}{l}\cdot \text { Enflux } \\
\cdot \text { Heddoko }\end{array}$ & $\begin{array}{l}\cdot \text { Motion } \\
\cdot \text { Vital signal }\end{array}$ & $\begin{array}{l}\text { Smart phone } \\
\text { display(3D avatar) }\end{array}$ & $\cdot$ Motion & $\begin{array}{l}\cdot \text { Chest, wrist } \\
\cdot \text { Arm, torso } \\
\cdot \text { Calf, leg }\end{array}$ \\
\hline & & $\begin{array}{l}\cdot \text { Stridalyzer } \\
\cdot \text { Sensoria } \\
\text { smart socks } \\
\cdot \text { Altra Halo } \\
\text { Tech Shoe } \\
\cdot \text { - Iofit golf }\end{array}$ & $\begin{array}{l}\text { Plantar pressure } \\
\text { change }\end{array}$ & $\begin{array}{l}\text { Smart phone } \\
\text { display }\end{array}$ & $\begin{array}{l}\cdot \text { Pressure } \\
\cdot \text { Acceleration }\end{array}$ & Sole \\
\hline \multirow{3}{*}{$\begin{array}{l}\text { Conve- } \\
\text { nience }\end{array}$} & \multirow{2}{*}{$\begin{array}{c}\text { Smart } \\
\text { controller }\end{array}$} & $\begin{array}{l}\cdot \text { Fin } \\
\cdot \text { Logbar ring } \\
\cdot \text { Motion ring }\end{array}$ & Finger motion & $\begin{array}{l}\text { - Text input } \\
\cdot \text { Device control }\end{array}$ & - Motion sensor & Finger \\
\hline & & $\cdot$ Myo & -Arm muscle motion & - Device control & $\begin{array}{l}\cdot \text { EMG } \\
\cdot \text { Acceleration }\end{array}$ & $\cdot$ Arm \\
\hline & Security & ·Nymi & $\cdot$ Heart rate pattern & $\begin{array}{l}\text {-Authentication } \\
\text {-Unlock }\end{array}$ & $\cdot \mathrm{ECG}$ & $\begin{array}{l}\cdot \text { Wrist } \\
\cdot \text { finger }\end{array}$ \\
\hline $\begin{array}{c}\text { Entertain- } \\
\text { ment }\end{array}$ & Pleasure & -Moff band & $\cdot$ Hand motion & -Sound & $\begin{array}{l}\cdot \text { Acceleration } \\
\text {-Gyroscope }\end{array}$ & $\cdot$ Wrist \\
\hline
\end{tabular}

\section{Conclusion and Discussion}

본 연구는 동작인식 스마트 의류제품의 특징적 유 형과 기능에 따른 기술 및 동향분석을 목적으로 현재 시판되고 있는 의류제품 사례를 착용하는 신체 영역 별 유형으로 분류하고, 사용목적 및 기능에 따라 각 각의 제품들을 기술적 측면에서 분석하였다. 동작인 식 스마트 의류제품은 머리와 얼굴, 몸통, 팔과 손, 다 리와 발 등 착용하는 신체위치에 따라 4 가지 유형으 로 분류되었다. 머리와 얼굴은 모자, 안경, 이어링 등 액세서리 형태로, 몸통은 벨트 등의 액세서리와 브라, 셔츠, 팬츠 등의 의복이 주류를 이루었고, 팔과 손은 팔찌, 밴드, 반지 등으로, 다리와 발은 발찌, 양말, 깔 창, 신발 등 텍스타일 형태의 다양한 아이템으로 개 발되고 있었다.

동작인식 스마트 의류제품은 특징적 기능에 따라 헬스케어, 스포츠, 생활편의, 엔터테인먼트 등 4가지 기능으로 분석할 수 있다. 한 제품에 한 가지 또는 여 러 가지 기능이 포함된 제품도 있었으며, 여러 기능 이 포함된 제품들은 주요 기능을 중심으로 분류하였
다. 헬스케어형은 건강한 삶을 위해 신체 보호 및 건 강 유지 관리와 질병 예방을 위한 기능 등이 포함된 제품으로 신체보호, 부상방지, 건강 모니터, 자세교정 등을 위한 제품으로 나타났다. 스포츠형은 효율적인 스포츠 능력 강화를 위해 운동정보 및 과학적인 피드 백을 제공하는 제품으로 신체 상태 및 운동레벨, 운 동 속도 등을 운동 모니터, 운동 코칭, 자세교정 등을 위한 제품으로 나타났다. 생활편의형은 간단한 동작 으로도 주변의 스마트 기기를 컨트롤할 수 있는 기능 을 제공하여 생활에 편리함을 주는 제품으로, 엔터테 인먼트형은 오락 및 게임 놀이인 가상공간에서 사실적 인 생동감으로 재미를 제공하는 제품으로 나타났다. 이 중 건강과 스포츠 분야에서 많은 제품이 편중되어 개발되고 있었다. 기술적 측면에서는 인식 내용 및 대상에 적합한 센서 기술과 데이터 전송 및 다양한 정보알림 등을 위한 통신기술, 취득된 데이터를 빠르 고 정확하게 분석하여 다양한 알림방법을 통해 피드 백할 수 있는 기술이 융합되어 나타나고 있었다.

본 연구는 모션인식 스마트 의류제품에 대한 사례 분석 연구로 구글 사이트에서 검색된 시판되고 있는 
의류제품과 학술지에서 언급된 모션인식 스마트 의류 제품만을 선정하여 주요 기능과 특성을 분석하였다는 한계를 지닌다. 앞으로 이에 대한 많은 연구가 필요하 며, IT 기술이 발달된 것과 같이 IT 기술과 융합된 동 작인식 스마트 의류제품도 다양하게 개발될 것이라 예상된다. 향후 후속연구에서는 빠른 변화와 발전을 보이는 IT 기술과 융합된 제품 중 동작인식 외에 다 른 기능을 가진 의류제품의 특성 및 기술적 측면에 대한 연구도 의미 있으리라 사료된다.

\section{References}

Athos. (n.d.). Athos. Retrieved March 3, 2017, from https://www.liveathos.com/athletes

BioSensive Technologies. (n.d.). Joule back ring. Retrieved March 3, 2017, from http://shopjoule.com

Cha, J. K., Ha, G. T., Lee, S. H., \& Kim, S. H., (2015). 가상 현실, 증강 현실 동작인식을 위한 웨어러블 센서 기술 [Wearable sensor technology for recognition of virtual reality and augmented reality motion]. Magazine of the IEEK, 42(6), 6370.

Chae, Y. S. (2014). A serious game design and prototype development for rehabilitation using KINECT tools. Journal of Korea Multimedia Society, 17(2), 248-256. doi:10.9717/kmms.2014.17.2.248

Chang, J. Y., Ryu, M. W., \& Park, S. C. (2014). Technology trends of range image based gesture recognition. Electronics and Telecommunications Trends, 29(1), 11-20.

Chang, L. (2016, March 19). Enflux smart clothing is the full-body wearable for the fitness fanatic. Digital Trends, Retrieved March 3, 2017, from https:/www.digitaltrends.com/health-fitness/enflu $\mathrm{X}$-smart-clothing

Choi, D. S. (2015, June). 웨어러블 디바이스의 진화스마트를 입은 제품들 [The evolution of wearable devices: Smart products]. Navercast, Retrieved March 3, 2017 from http://navercast.naver.com/magazine_contents.nhn?rid=1103\&conten ts $\mathrm{id}=92086$
Choi, H. S. (2014). Kinect-based motion recognition model for the $3 \mathrm{D}$ contents control. The Journal of the Korea Contents Association, 14(1), 24-29. doi:10.5392/JKCA.2014.14.01.024

Heo, G., \& Ha, J. E. (2015). Analysis of table tennis swing using action recognition. Journal of Institute of Control, Robotics and Systems, 21(1), 40-45. doi:10.5302/J.ICROS.2015.14.0078

Hexoskin. (n.d.). Hexoskin shirt. Retrieved March 3, 2017, from https://www.hexoskin.com

Hövding. (2013). Hövding 2.0 Airbag Helmet. Retrieved March 5, 2017, from https://shop.hovding.com/ bilder/artiklar/zoom/3315r_2.jpg

Industry Academic Cooperation Foundation Chosun University. (2016). Korean Patent No. 10-1613431. Deajeon: Korean Intellectual Property Office.

Jang, C. I. (2012). A study of the physical experience using serious game design traffic safety education for children applied using 3D depth gesture recognition technology. Journal of Korea Game Society, 12(6), 5-14. doi:10.7583/JKGS.2012.12.6.5 Jeon, S. H. (2015a, May 18). 차기 웨어러블은 '스마 트링' 이젠 '반지의 전쟁' [Next wearable is 'smart ring' now 'War of the Ring']. Newdaily, Retrieved March 3, 2017, from http://biz.newdaily.co.kr/news/ article.html?no=10074411

Jeon, S. H. (2015b, June 25). 피트니스용품에 부는 웨어러블 바람... "IT 입으니, 운동효과 '쑥"' [Wearable wearable wear for fitness... "IT wear, exercise effect 'mugwort'"]. Newdaily, Retrieved March 3, 2017, from http://biz.newdaily.co.kr/news/article. $\mathrm{html}$ ?no=10078002

Jins MEME. (n.d.). JINS MEME. Jins, Retrieved April 28, 2017, from https://jins-meme.com/en/products/ es

Jo, J. H. (2014, September 16), 국내 패션산업 '빅데 이터 활용이 관건' [Domestic fashion industry 'Big data utilization is key']. The International Textile. Fashion News, Retrieved March 3, 2017, from http://www.itnk.co.kr/news/articleView.html?idxn $\mathrm{o}=43811$ 
Jung, K. K., Park, H. S., \& Choi, W.-S. (2009). Development of daily life monitoring system using RFID. Journal of the Korea Society of Computer and Information, 14(7), 49-56.

Kim, B. J. (2013, September 23). 스마트한 자세 교정 기, '루모백' 출시 [Smart posture correction device, 'LUMOback' released]. APPSTORY, Retrieved March 3, 2017, from http://monthly.appstory.co.kr/it4604

Kim, M. K. (2013, October 16). 나이키 '퓨얼밴드 $\mathrm{SE}$ ' 공개, 11월 16일 출격 [Nike 'Fuel band SE' released, November 16th]. Kinews, Retrieved March 3, 2017, from http://www.kinews.net/news/article View.html?idxno $=40490$

Kim, S. K., Park, G. H., Jeon, S. H., Yim, S. H., Han, G. J., Choi, S. M., \& Choi, S. J. (2009). HMMbased motion recognition with 3-D acceleration signal. KIISE Transactions on Computing Practices, 15(3), 216-220.

Kim, S. K., \& Sung, K. (2014). Prospect of non-touch user interface technique. Journal of Advanced $\mathrm{Na}$ vigation Technology, 18(3), 242-247. doi:10.12673/ jant.2014.18.3.242

Kwon, S. H., Choi, Y. S., Lim, S. J., \& Joung, S. T. (2016). A implementation of user exercise motion recognition system using smart-phone. Journal of the Korea Academia-Industrial Cooperation Society, 17(10), 396-402. doi:10.5762/KAIS.2016. 17.10 .396

Lee, B. K. (2016). An implementation of Taekwondo action recognition system using multiple sensing. Journal of Korea Multimedia Society, 19(2), 436442. doi:10.9717/kmms.2016.19.2.436

Lee, H. J., \& Kwon, J. H. (2016, January). Gender differences in the pelvis \& shoulder motion during the gait using motion capture data. Proceedings of the Society of CAD/CAM Conference, Pyeongchang, 829-835.

Lee, J. G., Kim, J. H., \& Kim, T. Y. (2010). Fingertip extraction and hand motion recognition method for augmented reality applications. Journal of Korea Multimedia Society, 13(2), 316-323.
Lee, J. H. (2013, May 24). 스마트 UI/UX 기술 및 산 업 동향 [Smart UI/UX technology and industry trends] [LinkedIn Slide Share]. Retrieved March 3, 2017, from https://www.slideshare.net/opendori/ ui-ux-21842153

Lee, S. W. (2014, March 5). 헬스케어, 이번엔 스마 트 발찌? [Health care, this time smart Anklet?]. Tech Holic, Retrieved March 3, 2017, from http:// www.techholic.co.kr/news/articleView.html?idxno $=13461$

Lim, C. J., Kim, D. H., \& Kim, Y. J. (2012). 동작인 식기반 게임콘텐츠의 현황과 전망 [Current status and prospect of game contents based on motion recognition]. Magazine of the IEEK, 39(4), 18-26.

Omsignal. (n.d.). OMbra. Retrieved March 3, 2017, from https://www.omsignal.com/pages/ombra

Reinia. (2015, October 16). 웨어러블 안경 진스 밈 (JINS MEME), 안경 쓰니 내 피로가 보이네? [Wearable glasses JINS MEME, Can you see fatigue wearing glasses?]. TECHG, Retrieved March 3, 2017, from http://techg.kr/9863

Retisense. (2015). Stridalyzer. Retrieved May 3, 2017, from http://www.retisense.com

Ryu, H. S. (2015, March 5). 동작인식 기술 트렌드 및 시사점 [Motion recognition technology trends and implications]. Digieco Report, Retrieved May 3, 2017, from http:/www.digieco.co.kr/KTData/ Report/FILE/PDF/동작인식\%20기술\%20트렌 드 $\% 20$ 및 $\% 20$ 시사점201503051425517389545.pdf

Salted Venture. (2017). Iofit shoes. Retrieved May 3, 2017, from http://iofitshoes.com/iofit-golf-solution Sensoria. (n.d.). Sensoria Socks. Retrieved May 3, 2017, from http://store.sensoriafitness.com/sensoriafitness-smart-socks

Seo, J. H. (2013, July 10). 닥치고 동작 모션인식 2.0 키넥트 이후의 모션인식 기술 [Shut-down motion recognition 2.0 Kinect after motion recognition technology] [LinkedIn Slide Share]. Retrieved May 3, 2017, from https:/www.slideshare.net/Jonghoon $\mathrm{Seo} / 20-24091955$

Sin, Y. S. (2015, June). 올바른 걸음걸이를 만들어주 
는 스마트 깔창 '핏미' [Make a right gait smart insole 'Feetme']. Bizion, Retrieved May 3, 2017, from http://www.bizion.com/bbs/board.php?bo_table= gear\&wr id=811

Son, D. K. (2006). The conducting motion recognizing system using acceleration sensors for the virtual orchestra. Unpublished master's thesis, KAIST, Daejeon, Korea.

Son, Y. R. (2014, April 2). 사물 인터넷 시대에는 '센 서 플러스'가 돈된다 [Age the internet of things, 'sensor plus' is money]. MKnews, Retrieved May 3, 2017, from http://news.mk.co.kr/newsRead.php? year $=2014 \&$ no $=515380$

Sproutling. (2015). Baby monitor. Retrieved May 3, 2017, from http://sproutling.com

Suh, S. E., \& Roh, J. S. (2015). A study on smart fashion product development trends. The Research
Journal of the Costume Culture, 23(6), 1097-1115. doi:10.7741/rjec.2015.23.6.1097

Thalmic Labs. (n.d.). Myo. Retrieved March 3, 2017, from https://www.myo.com

Yoo, M. W. (2016, July). 동작인식을 위한 3D 센싱 기술 [3D sensing technology for motion recognition]. 계장기술 [Instrument technology], 102-111.

Yoon, H.-C., \& Park, J.-S. (2013). Gesture-based game character animation using motion data captured from the Kinect sensor. Journal of The Korean Society for Computer Game, 26(2), 147-153.

Yoon, H. J. (2014, July 26). IOT/웨어러블 디바이스 에서의 동작인식 기술 및 활용분야 [IOT/wearable device motion recognition technology and application field] [LinkedIn Slide Share]. Retrieved May 3, 2017, from https:/www.slideshare.net/firehj/io-t2014-07-26 